EESTI NSV TEADUSTE AKADEEMIA TOIMETISED. 28. KOIDE GEOLOOGIA. 1979, NR. 1

ИЗВЕСТИЯ АКАДЕМИИ НАУК ЭСТОНСКОП ССР, ТОМ 28 ГЕОЛОГИЯ, 1979, 시 I

\title{
СТАТИСТИЧЕСКИЕ МОДЕЛИ ПРОГНОЗА ВОДОПРИТОКОВ В ШАХТЫ И РАЗРЕЗЫ ЭСТОНСКОГО МЕСТОРОЖДЕНИЯ ГОРЮЧИХ СЛАНЦЕВ
}

В крупных месторождениях широко применяется прогнозирование шахтных водопритоков с помощью эмпирических зависимостей, установленных между величинами водопритоков и показателями разных природных и искусственных факторов (Попов, Скабалланович, 1974). Что касается Эстонского месторождения горючих сланцев, то здесь количественно оценены связь между весенними водопритоками и осенне-зимними атмосферными осадками (Скригелло, Полянина, 1959), зависимость шахтных водопритоков от простирания выработок и затухание неравномерности притока с глубиной разработки (Газизов, 1971). Ввиду небольшой глубины выработок и трещинно-карстового характера подземных вод климатические условия играют в обводненности Эстонского месторождения немаловажную роль. Предполагается даже, что гидрометеорологические факторы являются единственными, с которыми статистически значимо коррелируются прогнозируемые водопритоки Эстонского месторождения (Леви, 1973).

Ниже на основе статистического анализа показано, что величины водопритоков Эстонского месторождения горючих сланцев в значительной мере определяются также показателями горнотехнических мероприятий и геологического строения. Выявленный комплекс притокообразующих факторов легко поддается количественной оценке и в отличие от метеорологических факторов является заранее определяемым.

Статистические прогнозные модели водопритоков построены на основе результатов регрессионного и дисперсионного анализов, проведенных на ЭВМ «Минск-32» по соответствующим программам (Петерсен и др., 1976).

Структура массива исходных данных моделей. Зависимыми переменными (прогнозируемыми параметрами) приняты водопритоки в шахты и разрезы:

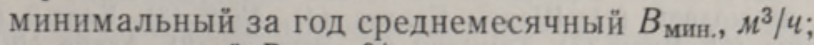

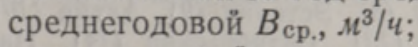

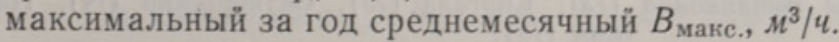

Допускается, что эти показатели водопритока опорные в водно-хозяйственных расчетах. В качестве независимых переменных (требуемых для прогнозирования параметров) рассматривался ряд выведенных и оцененных нами параметров, из которых значимыми оказались следующие.

А. Искусственные факторы:

1) площадь отработанной части шахты или разреза (при камерной разработке сланца с внутрикамерными целиками) $\Pi, \kappa м^{2}$; 

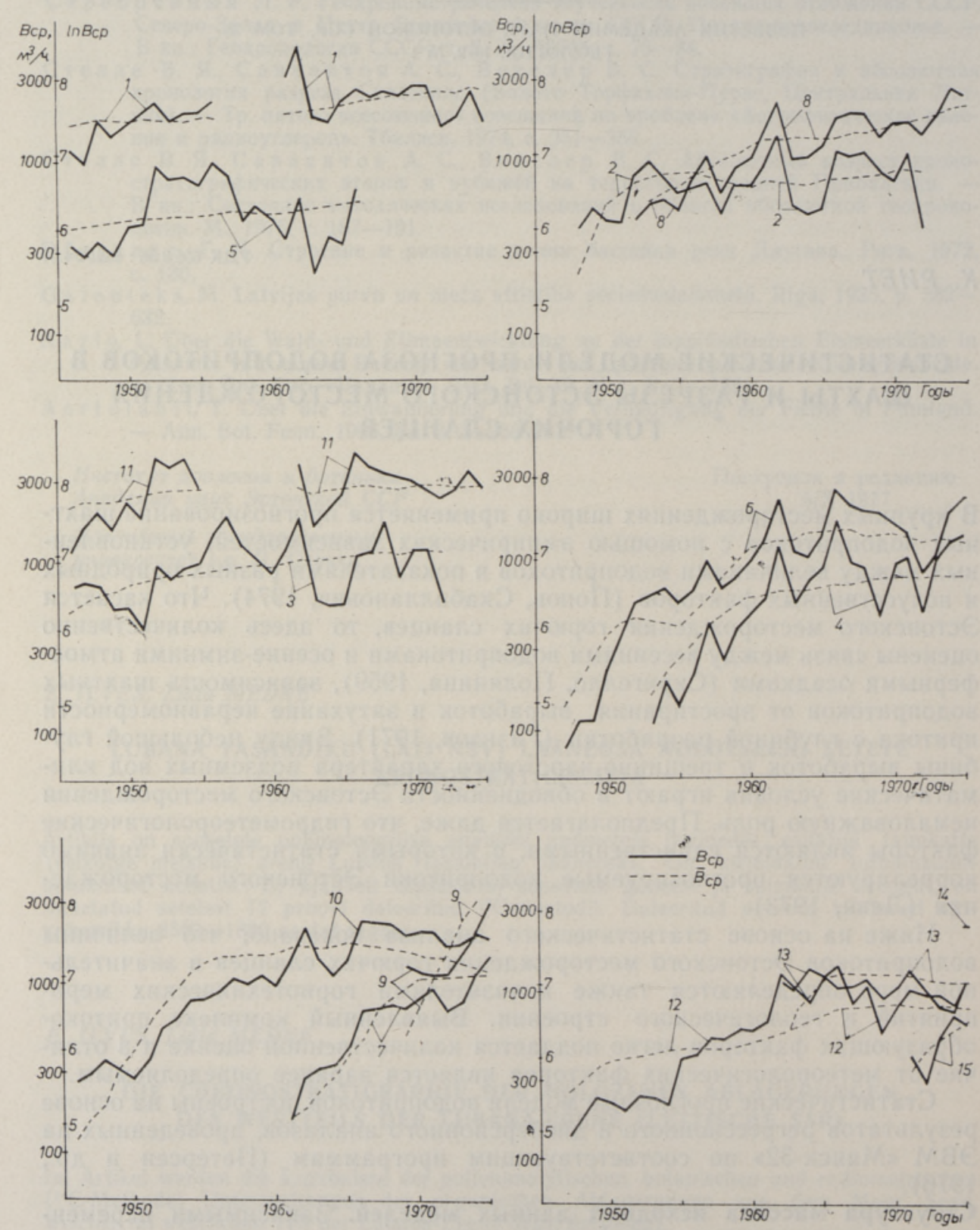

Среднегодовой водоприток $B_{\mathrm{cp}}$. в шахты и разрезы Эстонского месторождения горючего сланца и его оценка $\bar{B}_{\text {ср. }}$ по модели (1). Шахты Кохтла (1), № 2 (2), Кява-2 (3), № 4 (4), Кукрузе (5), Сомпа (6), Виру (7), Таммику (8), Эстония (9), Ахтме (10) и Кивиыли (11) и разрезы Вийвиконна (12), Сиргала (13), Октябрьский (14), Нарвский (15).

2) параметр $C\left(\kappa M^{-2}\right)$, характеризующий суммарное влияние водоотлива из других шахт и разрезов на величину водопритока в данную шахту (разрез), причем

$$
C=\sum_{k=1}^{n-1}\left(P_{k}-p_{k}\right)^{-2}+1,
$$


где $P_{k}$ - расстояние между центрами тяжести отработанных частей рассматриваемой и $k$-той другой (соседней) действующей шахты (разреза), $\kappa м ; p_{k}=0,56 \Pi^{0,5}$ - приведенный радиус $k$-той другой действующей шахты (разреза), $к м ; n-$ количество действующих шахт и карьеров на месторождении (данные по отдаленным шахтам и карьерам с $P_{k}>6 \kappa м$ при подсчете параметра можно опустить).

Б. Природные факторы, вычисляемые как средние значения в пределах отработанной части шахты или разреза:

3) глубина подошвы промпласта от поверхности земли $\Gamma, M$;

4) мощность четвертичного покрова $M, \mu$;

5) абсолютная отметка поверхности земли $A, M$.

Следует отметить, что величины параметров природной обстановки меняются в пределах одной шахты (разреза) во времени относительно мало, а значения параметров искусственных факторов со временем существенно увеличиваются.

Каждое наблюдение совокупности исходных данных моделей описывает один год одной работающей шахты (разреза) и имеет по каждой переменной определенное численное значение. Всего получено 299 наблюдений в соответствии с наличием материалов о замерах водопритоков с 1946 по 1975 г. по 11 шахтам и 4 разрезам (рисунок). Кроме того, по принадлежности к отдельным шахтам и разрезам наблюдения сгруппированы в ряд дисперсионных уровней. Таким образом, в моделях учитывается еще и комплекс численно не выражаемых условий притокообразования разных шахт (разрезов) или их групп.

Описание моделей. Проанализировано более 100 вариантов статистических моделей водопритока в целях выявления тех, которые имеют наилучшие прогнозные свойства. Критериями пригодности служили максимальные значения множественного коэффициента корреляции $R$, по меньшей мере $95 \%$-ная значимость регрессии отдельных независимых переменных (по дисперсионному отношению), а также логическая устойчивость модели в целом. Наиболее подходящими оказались модели, в которых водопритоки связаны с искусственными факторами по степенному, а с природными по экспоненциальному закону (для Донбасса, например, характерны аналогичные зависимости степенного типа (Попов, Скабалланович, 1974)).

Рекомендуемая нами модель прогноза водопритоков в действующие шахты и разрезы Әстонского месторождения имеет при $B_{\text {мин., }} B_{\text {ср. и }}$ $B_{\text {макс. одинаковую структуру }}$

$$
\ln \bar{B}_{1}=a_{1,0}+a_{1, i}+b_{1,1} \ln \Pi+b_{1,2} \Gamma+b_{1,3} M+b_{1,{ }_{4}} A,
$$

где $\bar{B}_{1}$ - ожидаемое значение (оценка) водопритока, $M^{3} / 4, a_{1,0}$, $a_{1, i}, b_{1,1}, \ldots, b_{1,4}$ - коэффициенты модели, $i=1, \ldots, 15$ в соответствии с рассматриваемой шахтой (разрезом). Для сравнения приведены коэффициенты модели по заброшенным ныне шахтам (табл. 1$). R$ для модели

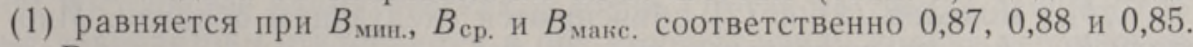

Рекомендуемая модель прогноза водопритоков в запланированные шахты и разрезы приобретает при $B_{\text {мин., }} B_{\text {ср. и }} B_{\text {макс. вид: }}$

$$
\ln \bar{B}_{2}=a_{2,0}+a_{2, i}+b_{2,1} \ln \Pi+b_{2,2} \Gamma+b_{2,3} M+b_{2,4} A+b_{2,5} \ln C,
$$

где $\bar{B}_{2}$ - ожидаемое значение (оценка) водопритока, $\mu^{3} / u, a_{2,0}, a_{2, i}$, $b_{2,1}, \ldots, b_{2,5}$ - коэффициенты модели, $i=1$ для шахт, $i=2$ для разрезов на выходе ордовика, а $i=3$ для разрезов в районе распространения девонских отложений (табл. 2$). R$ для модели (2) составляет при $B_{\text {мин., }}$

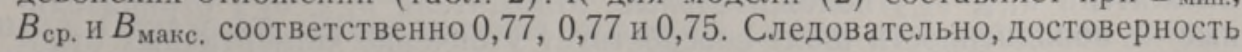


Таблица 1

Оценки коэффициентов модели (1)

\begin{tabular}{|c|c|c|c|c|}
\hline \multirow{2}{*}{$\begin{array}{c}\text { Дисперсионные уровни } \\
\text { (шахты и разрезы) } \\
\text { и переменные }\end{array}$} & \multirow{2}{*}{$\begin{array}{c}\text { Коэффи- } \\
\text { циенты }\end{array}$} & \multicolumn{3}{|c|}{ Оценки коэффициентов } \\
\hline & & $B_{\text {мин. }}$ & $B_{\text {cp. }}$ & $B_{\text {маке. }}$ \\
\hline & $a_{1,0}$ & 13,9339 & 14,7556 & 16,1203 \\
\hline Шахта Кохтла & $a_{1,1}$ & 0,1843 & $-0,0199$ & $-0,3339$ \\
\hline Шахта № 2 & $a_{1,2}$ & 0,9342 & 0,8981 & 1,1863 \\
\hline Шахта Кява-2 & $a_{1,3}$ & 0,6633 & 0,9592 & 1,3501 \\
\hline Шахта № 4 & $a_{1,4}$ & $-0,0431$ & 0,1414 & 0,4013 \\
\hline Шахта Кукрузе & $a_{1,5}$ & 0,5710 & 0,8436 & 1,2934 \\
\hline Шахта Сомпа & $a_{1,6}$ & 0,4383 & 0,3548 & 0,5273 \\
\hline Шахта Виру & $a_{1,7}$ & 1,3124 & 1,1389 & 1,4218 \\
\hline Шахта Таммику & $a_{1,8}$ & 1,5629 & 1,5543 & 1,8859 \\
\hline Шахта Эстония & $a_{1,9}$ & $-0,0339$ & $-0,2121$ & 0,1042 \\
\hline Шахта Axтме & $a_{1,10}$ & $-0,2930$ & $-0,5031$ & $-0,5036$ \\
\hline Шахта Кивиыли & $a_{1,11}$ & $-0,4005$ & $-0,5892$ & $-0,7592$ \\
\hline Разрез Вийвиконна & $a_{1,12}$ & $-1,8747$ & $-1,8953$ & $-2,3996$ \\
\hline Разрез Сиргала & $a_{1,13}$ & $-1,4138$ & $-1,2912$ & $-1,7792$ \\
\hline Разрез Октябрьский & $a_{1,14}$ & 1,1425 & 0,9249 & 0,2858 \\
\hline Разрез Нарвский & $a_{1,15}$ & $-2,7501$ & $-2,3046$ & $-2,6807$ \\
\hline$\Pi$ & $b_{1,1}$ & 0,2440 & 0,2579 & 0,2864 \\
\hline$\Gamma$ & $b_{1,2}$ & 0,0594 & 0,0581 & 0,0436 \\
\hline$M$ & $b_{1,3}$ & $-0,4407$ & $-0,5816$ & $-0,6087$ \\
\hline$A$ & $b_{1,4}$ & $-0,1438$ & $-0,1405$ & $-0,1462$ \\
\hline
\end{tabular}

Оценки коэффициентов модели (2)

Таблича 2

\begin{tabular}{l|c|r|r|r}
\hline \multirow{2}{*}{$\begin{array}{l}\text { Дисперсионные уровни (группы } \\
\text { шахт и разрезов) и переменные }\end{array}$} & $\begin{array}{r}\text { Коэффи- } \\
\text { циенты }\end{array}$ & \multicolumn{3}{|c}{ Оценки коэффищиентов } \\
\cline { 3 - 5 } & & $B_{\text {мнн. }}$ & $B_{\text {ср. }}$ & $B_{\text {макс. }}$ \\
\hline & $a_{2,0}$ & 9,4819 & 9,6029 & 9,4619 \\
Шахты на выходе $O_{2-3}$ & $a_{2,1}$ & 0,3349 & 0,2274 & 0,1959 \\
Разрезы на выходе $O_{2}$ & $a_{2,2}$ & $-0,6958$ & $-0,5324$ & $-0,5194$ \\
Разрезы на выходе $D_{2}$ & $a_{2,3}$ & $-1,5963$ & $-0,9047$ & $-0,5963$ \\
$\Pi$ & $b_{2,1}$ & 0,2321 & 0,2439 & 0,2743 \\
$\Gamma$ & $b_{2,2}$ & 0,0392 & 0,0293 & 0,0152 \\
$M$ & $b_{2,3}$ & $-0,1803$ & $-0,2883$ & $-0,3004$ \\
$A$ & $b_{2,4}$ & $-0,0683$ & $-0,0513$ & $-0,0312$ \\
$C$ & $b_{2,5}$ & $-0,2912$ & $-0,1383$ & $-0,0505$
\end{tabular}

прогнозов по модели (2) ниже, чем по модели (1), но зато модель (2) не содержит членов $a_{1}, i$, определяемых лишь после нескольких лет работы шахты (разреза).

Физическое содержание моделей. Знаки множителей $b_{1,1}, \ldots, b_{1,4}$ и $b_{2,1}, \ldots, b_{2,5}$ моделей (1) и (2) объясняются следующим образом. Множители $b_{1,1}, b_{2,1}$ положительные потому, что с расширением отработанных площадей растут горизонтальные притоки подземных вод со стороны, а еще быстрее прибавляется вертикальный приток поглощающихся непосредственно над горными выработками вод. С погружением промпласта наблюдается утолщение осушаемой кровли и увеличение горизонтальных водопритоков, а тем самым возрастает и фильтрационное сопротивление породы протекающим сверху водам. При нынешних глубинах разработки сланца преобладает первая тенденция, так как множители $b_{1,2}, b_{2,2}$ положительные. Множители $b_{1,3}, b_{2,3}$ отрицательные - обводненности шахт способствует утончение четвертичных отло- 
жений, препятствующих инфильтрации атмосферных осадков, относительно водоупорного слоя. Расположение шахт и разрезов в более нижней части месторождения, т. е. в районе естественного притока подземных и наземных вод, сопровождается также бо́льшей обводненностью, о чем свидетельствуют отрицательные значения $b_{1,4}$ и $b_{2,4}$. Отрицательным является и множитель $b_{2,5}$ - развертывание горных работ и, соответственно, водоотлива по всему месторождению приводит к истощению запасов подземных вод местности.

Абсолютные величины множителей $b_{1,1}, \ldots, b_{1,4}$ и $b_{2,1}, \ldots, b_{2,5}$ меняются

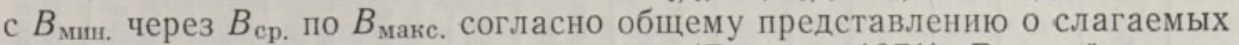
годового гидрографа шахтных притоков (Газизов, 1971). В сухой период года, характеризуемый $B_{\text {мин, }}$ шахтные и разрезные воды формируются в большой степени за счет горизонтального притока подземных вод. В таком случае наибольшее влияние оказывают мощность осушаемой толщи и рельеф местности, на что указывают максимальные значения $\left|b_{1,2}\right|,\left|b_{2,2}\right|$ и $\left|b_{1,4}\right|,\left|b_{2,4}\right|$. Именно в сухое время года обнаруживается в модели (2) четкое содействие водоотлива из соседних шахт, описы-

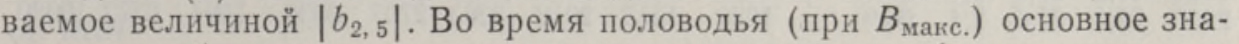
чение приобретает непосредственная вертикальная инфильтрация воды в горные выработки. Тогда наблюдаются максимальные величины $\left|b_{1,1}\right|,\left|b_{2,1}\right|$ и $\left|b_{1,3}\right|,\left|b_{2,3}\right|$ - соответственно множители параметров отработанной площади и мощности четвертичного покрова. Более четко эти закономерности проявляются у модели (2). В модели (1) разнообразные условия формирования водопритоков отражаются главным образом в изменчивости членов $a_{1, i}$, в которых заключается также влияние самостоятельно здесь не выходящего параметра $C$.

По членам $a_{1, i}$ модели (1) и $a_{2, i}$ модели (2) видно, что при остальных равных условиях водопритоки в шахты превышают водопритоки в разрезы. Это объясняется тем, что в отвалах разрезов сохраняется некоторое количество воды, в то время как отработанная площадь шахт осушается в большей степени. Следует еще добавить, что существующие разрезы, определяющие значения членов $a_{1,12}, a_{1,13}$ и $a_{2,2}$, расположены на заболоченной равнине, а шахты сооружены в основном в карстовых районах с более благоприятными условиями восполнения подземных вод. Что касается Нарвского разреза $\left(a_{1,15}\right.$ и $\left.a_{2,3}\right)$, то он находится в особых условиях - здесь в кровле промпласта представлены девонские водоупорные мергели и доломиты, не встречающиеся в остальной разрабатываемой части месторождения.

Применимость моделей. По рисунку видно, что полученная по модели (1)

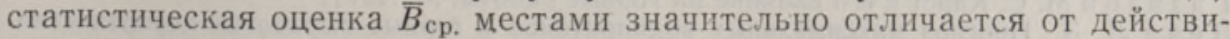
тельного среднегодового водопритока $B_{\text {cp. }}$ При $B_{\text {мин. и }} B_{\text {макс. наблюда- }}$ ется аналогичная картина. В сущности, оценка водопритока $B$ является приближением тренда, описывающего изменение водопритоков при мнимом постоянстве климатических условий. От такого тренда действительные водопритоки отклоняются в обе стороны ввиду крайне неравномерных климатических условий отдельных годов. (Как известно, особенности климата будущего практически не предсказываемы и поэтому приведенные выше модели не содержат гидрометеорологических параметров). Существует также некоторая ошибка аппроксимации тренда, особенно у модели (2), вызванная схематизацией сложных естественных процессов в простых моделях.

По указанным выше причинам модели (1) и (2) не гарантируют полного совпадения действительных величин водопритоков с прогнозными. Однако на основе массива исходных данных при заданных условиях соответствующими вычислениями (Петерсен и др., 1976) можно опре- 
Величины притокообразующих факторов и прогноз водопритоков в шахты

\begin{tabular}{|c|c|c|c|c|c|c|c|c|c|c|c|c|c|c|}
\hline \multirow[b]{4}{*}{ 苛 } & \multirow{2}{*}{\multicolumn{5}{|c|}{$\begin{array}{c}\text { Притокообразующие } \\
\text { факторы }\end{array}$}} & \multicolumn{9}{|c|}{ Водопритоки, $\mu^{3} / u$} \\
\hline & & & & & & \multicolumn{3}{|c|}{$B_{\mathrm{Mm}}}$. & \multicolumn{3}{|c|}{$B_{\text {ep. }}$} & \multicolumn{3}{|c|}{$B_{\text {маке }}$} \\
\hline & \multirow[b]{2}{*}{$\begin{array}{l}\stackrel{2}{*} \\
\stackrel{2}{2} \\
\&\end{array}$} & \multirow[b]{2}{*}{$\stackrel{\square}{2}$} & \multirow[b]{2}{*}{$\underset{\Sigma}{\ddot{\Sigma}}$} & \multirow[b]{2}{*}{$\begin{array}{l}\overline{8} \\
\overline{7}\end{array}$} & \multirow[b]{2}{*}{\begin{tabular}{l}
\multirow{1}{*}{} \\
\multirow{2}{*}{} \\
0
\end{tabular}} & \multirow[b]{2}{*}{ 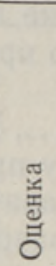 } & $\begin{array}{r}90 \% \\
\text { дове } \\
\text { ный } \\
\text { тер } \\
\end{array}$ & $\begin{array}{l}\text { ный } \\
\text { итель- } \\
\text { ин- } \\
\text { зал }\end{array}$ & & $\begin{array}{r}90 \% \\
\text { дове } \\
\text { ный } \\
\text { тер } \\
\end{array}$ & $\begin{array}{c}\text {-ный } \\
\text { ритель } \\
\text { ин- } \\
\text { вал }\end{array}$ & & $\begin{array}{c}90 \%- \\
\text { довер } \\
\text { ный } \\
\text { терв }\end{array}$ & $\begin{array}{l}\text { ный } \\
\text { итель- } \\
\text { ин- } \\
\text { ал } \\
\end{array}$ \\
\hline & & & & & & & 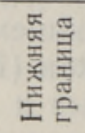 & 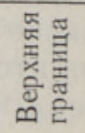 & 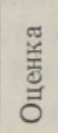 & 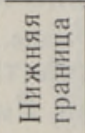 & 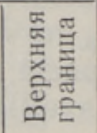 & 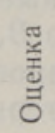 & 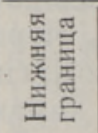 & 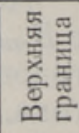 \\
\hline
\end{tabular}

$\begin{array}{lllll}1980 & 12,4 & 26,5 & 2,4 & 65,3 \\ 1985 & 15,2 & 27,5 & 2,5 & 65,3 \\ 1990 & 17,9 & 28,8 & 2,4 & 66,0 \\ 2000 & 22,6 & 30,6 & 2,4 & 66,9\end{array}$

1995

$\begin{array}{lllllll}2000 & 12,5 & 45,7 & 2,8 & 54,9 & 1,04 & 2780\end{array}$

\section{Таммику}

$\begin{array}{llllllllr}1390 & 1124 & 1717 & 2764 & 2294 & 3329 & 7125 & 5687 & 8932 \\ 1480 & 1194 & 1835 & 2908 & 2407 & 3512 & 7413 & 5898 & 9317 \\ 1573 & 1281 & 1932 & 3144 & 2625 & 3767 & 7891 & 6343 & 9815 \\ 1628 & 1315 & 2012 & 3263 & 2707 & 3932 & 7991 & 6372 & 10020\end{array}$

Уус-Кивиыли

$\begin{array}{llllllll}1926 & 2849 & 2866 & 2404 & 3419 & 3679 & 3020 & 4481\end{array}$

$\begin{array}{llllllll}2303 & 3355 & 3468 & 2929 & 4108 & 4861 & 4023 & 5875\end{array}$

делить для прогнозной оценки водопритока доверительные интервалы любой обеспеченности.

В качестве примера в табл. 3 приведены для шахты Таммику и перспективной шахты Уус-Кивиыли величины притокообразующих факторов и вычисленные на их основе соответственно по моделям (1) и (2) прогнозы водопритоков с $90 \%$-ным доверительным интервалом.

Простые и доступные прогнозные модели водопритоков (1) и (2) рекомендуется применять в горном деле и водном хозяйстве, особенно при предварительных изысканиях. По мере прибавления фактических данных о водопритоках в шахты и разрезы Эстонского месторождения со временем расширяются и возможности усовершенствования статистических моделей прогноза водопритоков.

\section{ЛИТЕ Р А Т Р А}

Г а з и з о в М. С. Карст и его влиянне на горные работы. М., 1971.

Л е в и Л. 3. Прогноз максимальных водопритоков в горные выработки вероятностностатистическими методами. М., 1973.

Петерсен И., Кукс Я., В й йман Э., К аролин М., Л елумеэс Э., Пукк К., Т и й т с Т., Х у р т Т. Прикладные программы по математической статистике для ЭВМ «Минск-32». Таллин, 1976.

Попов В. С., Ск аб аллано вич І. А. (ред.). Гідрогеологія та инженерна геологія глибоких горизонтів Донбасу. Київ, 1974.

Ск ри гелло О. Б., Поля н и н М. А. Прогноз притоков воды в шахты в карстовых областях, - Разведка и охрана недр, 1959, № 9, с. 47-52.

Институт геологии

Академии наук Эстонской ССР
Поступила в редакцию 22/XII 1977 


\section{EESTI POLLEVKIVIMAARDLA KAEVANDUSTE JA KARJÄ̈RIDE VEE JUURDEVOOLU STATISTILISED PROGNOOSIMUDELID}

Prognoosimudelid on saadud Eesti põlevkivimaardla andmestiku töötlemisel regressioonja dispersioonanalüüsi teel. Prognoositavad parameetrid on aasta minimaalne kuu keskmine, aasta keskmine ja aasta maksimaalne kuu keskmine vee juurdevool kaevandusse (karjääri). Prognoosi lähteparameetriteks on võetud kaevanduse (karjääri) kaevandatud pindala, naaberkaevanduste (-karjääride) vee kōrvalduse mõju kajastav näitaja, tootsa kihi lamami sügavus, pinnakatte paksus ja maapinna absoluutne kõrgus. On arvestatud ka arvuliselt väljendamatuid vee juurdevoolu kujunemise tingimusi. Soovitatakse kasutada kaht prognoosimudelit - mudel (1) sobib olemasolevate ja mudel (2) kavandatavate kaevanduste ning karjääride vee juurdevoolu ennustamiseks. Mudelite koefitsientide märgid ja arvväärtused on kooskõlas kaevandus- ja karjäärivee tekketingimustega.

\section{K. RIET}

\section{STATISTICAL FORECAST MODELS OF WATER FLOW IN MINES AND OPEN-CAST PITS OF ESTONIAN OIL SHALE}

The forecast models discussed have been obtained with the help of regression and dispersion analysis. The parameters to be forecasted are the annual minimal average per month, and annual maximal average of water flow into the mine (open-cast pit). For obtaining data for the forecast, the following indices have been used: the area of the exploitable mine (open-cast pit), the index reflecting the effect of the removal of water from neighbouring mines (open-cast pits), the depth at which the productive stratum is deposited, the thickness of the surface coverage, and the absolute height of the earth surface. Account has also been taken of the conditions under which the water flow is formed, and which, however, cannot be conveyed in figures. Two models are recommended: (1) which suits for prognosing the water flow in the existing, and (2) the unexisting exploitable mines. The coefficients and numerical values are in conformity with the formation conditions of water in mines and open-cast pits. 